\title{
Estimating the breeding population of an elephant seal colony from a single census
}

\author{
Richard Condit ${ }^{*}$, Sarah G. Allen ${ }^{2}$, Daniel P. Costa ${ }^{1}$ Sarah Codde ${ }^{2}$, P. Dawn Goley ${ }^{3}$, \\ Burney J. Le Boeuf ${ }^{1}$, Mark S. Lowry ${ }^{4}$, Patricia Morris ${ }^{1}$ \\ 1 Institute for Marine Sciences, University of California, Santa Cruz, USA \\ 2 National Park Service, Point Reyes National Seashore, Point Reyes Station, CA 94956, \\ USA \\ 3 Department of Biological Sciences, Humboldt State University, Arcata CA 95521, USA \\ 4 Marine Mammal and Turtle Division, Southwest Fisheries Science Center, La Jolla, \\ CA 92037, USA \\ *condit@gmail.com
}

\begin{abstract}
Our aim was to develop a method for estimating the annual number of female elephant seals pupping in a colony from a single count. This is difficult because breeding females are not synchronous so there is no time when the entire population is present. We applied models that describe arrival and departure behavior to account for those missed in any one count and calculated correction factors that yield total population from any single count throughout a season. At seven colonies in California for which we had multiple female counts per year, we found consistent timing in arrival and departure both within and between sites for as long as 50 years. This meant that the optimal correction factor, the date when the maximum number of females was onshore, was consistent. At Point Reyes, a female count on 27 or 28 Jan can be multiplied by 1.15 to yield the total female population; at Año Nuevo Island, the correction was 1.17 on 25-26 Jan; and at Año Nuevo Mainland, 1.13 on 28-30 Jan. Correction factors at Channel Island colonies and King Range were also 1.13. Across the colonies studied, the factor 1.15 multiplied by a female count between 26 and 30 Jan was close to optimal, and this provides a method for estimating the female population size at colonies not yet studied. Our method can produce population estimates with minimum expenditure of time and resources and will facilitate monitoring of the elephant seal population size over its entire range.
\end{abstract}

\section{Introduction}

Northern elephant seals (Mirounga angustirostris) are large marine predators that aggregate on land at predictable times to raise pups, allowing straightforward counts of breeding females [[1,2]]. There is never a day, however, when all females are ashore because some depart for all have arrived. Models are thus required to estimate arrival and departure curves and the total number of females breeding on the colony [ $3[5]$.

Our objective here is to use these models to generate correction factors that convert a single count near the peak of the breeding season into an estimate of the total number of females using the colony in that year. We develop correction factors for seven colonies, then evaluate the consistency of census timing and resulting correction factors 
across sites. Accurate population estimates from single counts will allow efficient and inexpensive censusing of many colonies, especially valuable at sites that are difficult to access. This will contribute to long-term monitoring of the elephant seal pup production at all its major colonies from Mexico to Canada [6]].

\section{Materials and Methods}

\section{Field sites}

We used censuses of breeding females at seven colonies (Fig 1), including all years from 1968-2018 at Año Nuevo Island, 1977-2018 at Año Nuevo Mainland, 1981-2019 at Point Reyes, 2018-2020 at King Range, plus 2010 and 2013 at San Nicolas Island and 2013 at San Miguel Island and Santa Rosa Island.

Figure 1. Elephant seal breeding colonies. Locations of the seven colonies analyzed, indicated by red arrows: San Nicolas Island (SNI), Santa Rosa Island (SRI), San Miguel Island (SMI), Año Nuevo island and mainland (ANI \& ML), Point Reyes (PR), King Range (KR).

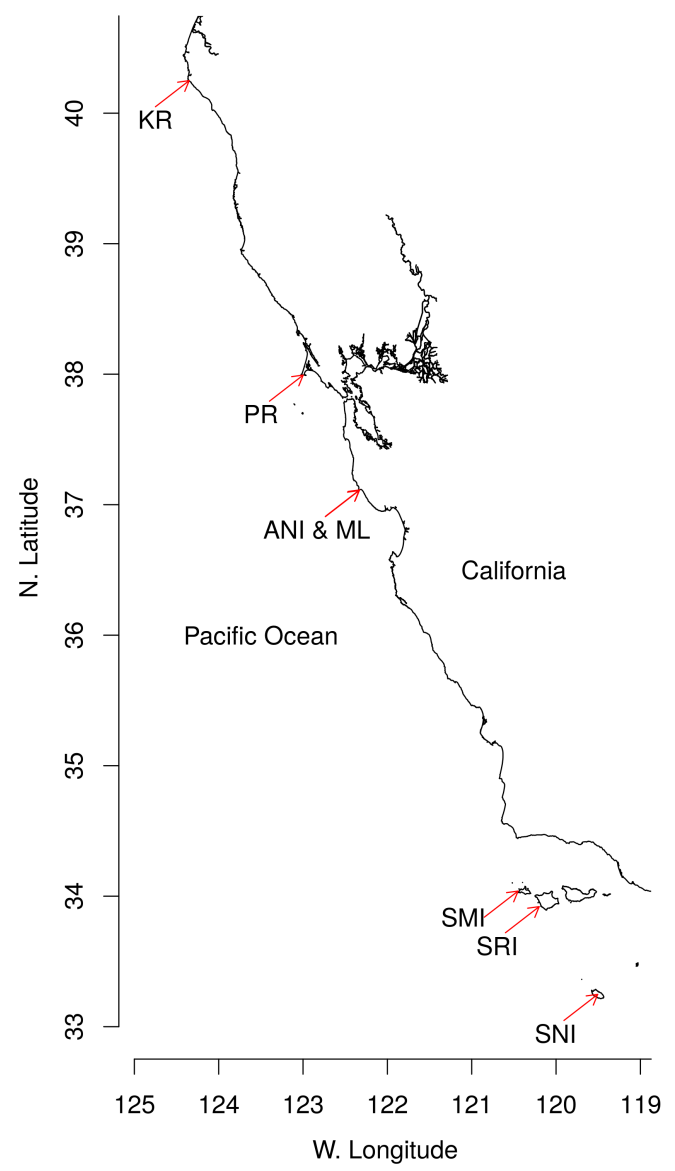




\section{Female counts}

A single datum is a complete count of all females onshore at one colony on one day. At Año Nuevo, we usually counted from high points on dunes near the females [[2], but counts from airplanes or drones were used to support ground counts on a few days when numbers were at their highest. Aerial counts confirmed that ground counts had no consistent bias. Most counts at Point Reyes were done from high cliffs overlooking the animals, allowing excellent visibility, but some were done on beaches immediately adjacent to the females [ [7]]. Counts at King Range were done from close proximity to the colony or from a trail within 50-100 m [ 8] ]. At the Channel Islands, all counts were made from photographs taken from an airplane and have been evaluated for accuracy elsewhere $[[9,10]]$.

\section{Census model}

We define the census curve as the count of females through time during the breeding season. It is bell-shaped, starting from zero females in mid-December, peaking near the end of January, then dropping again until early March (Fig 2). Rothery and McCann [[3] and Condit et al. [5]] developed models to describe the census curve precisely. The models yield estimates of daily arrival and departure curves, $a(t)$ and $d(t)$ (the total number of animals arriving [departing] on one day $t$ ), and cumulative arrival and departure curves, $A(t)=\sum_{1}^{t} a(i)$ and $D(t)=\sum_{1}^{t} d(i)$ (number of females arrived [departed]) through day $t$ ). The estimated census curve on day $t$ is

$$
C(t)=A(t)-D(t)
$$

The model parameters are estimated by fitting $C(t)$ as closely as possible to the observed daily counts (Fig 2). Further details are presented in Condit et al. [[5]].

Here we add one substantial improvement. In earlier papers, we analyzed all years independently, estimating a set of parameters for each [[2,5]]. Here, we fit the entire ensemble of counts at one colony in a single hierarchical model, with year as a random effect [11]]. Taking the mean arrival date as an example, each year has an estimated date, and those dates across all years are fitted to a Gaussian distribution known as the hyper-distribution, including one hyper-mean arrival date and one hyper-standard-deviation (Table 1). Each of the model parameters was constrained by a Gaussian hyper-distribution except total population. The advantage of the hierarchical method arises in years having too few counts to fit the full arrival-departure model. In previous papers, we omitted those years from calculations [[2]5]. With a multi-year model, they can be included because the arrival and departure curves from other years provide support (Fig 2).

The multi-year hierarchical model was fitted to five sets of data: the island and mainland colonies at Año Nuevo, Point Reyes, King Range, and the three Channel Islands combined; data were insufficient to model the Channel Islands separately. We did not attempt to create a single grand model with both colony and year levels, since there were too few colonies to support a random effect. All parameters of the model (Table 1) for those five datasets were estimated with a Bayesian Monte Carlo procedure, producing a posterior distribution and thus $95 \%$ credible intervals for parameters and the statistics calculated from parameters (for details on parameter-fitting, see references [5, 12 13). To compare colonies and to evaluate consistency of the census timing across years, we used the mean arrival date each year, $\hat{a}_{i}$, as fitted by the model, and the date of the maximum female census calculated from the fitted census curve $C(t)$ in each year. 
Figure 2. Daily female counts through time and fitted census curves. Black points are observed counts. The black, bell-shaped curve is the fitted census curve, $C(t)$; the blue dotted curve is the estimated cumulative arrival curve, $A(t)$; and the dotted red curve the cumulative departure curve, $D(t) . A(t)$ and $D(t)$ reach an asymptote at the total population of females using the colony in year $i, N_{i}$. Year 2016 at Año Nuevo Island (ANI) and 2019 at Point Reyes (PR) illustrate cases where the model generated standard curves even with counts too few to constrain the shape. It works because other years with ample counts set arrival curves via hyper-parameters $\mu_{a}$ and $\mu_{s}$ (Table 1). Other abbreviations: ANML, Año Nuevo Mainland; SNI, San Nicolas Island; KR, King Range. Range of the vertical axis varies greatly, but the dates on the horizontal axis are identical; vertical lines are at 1 Jan, 1 Feb, 1 Mar.
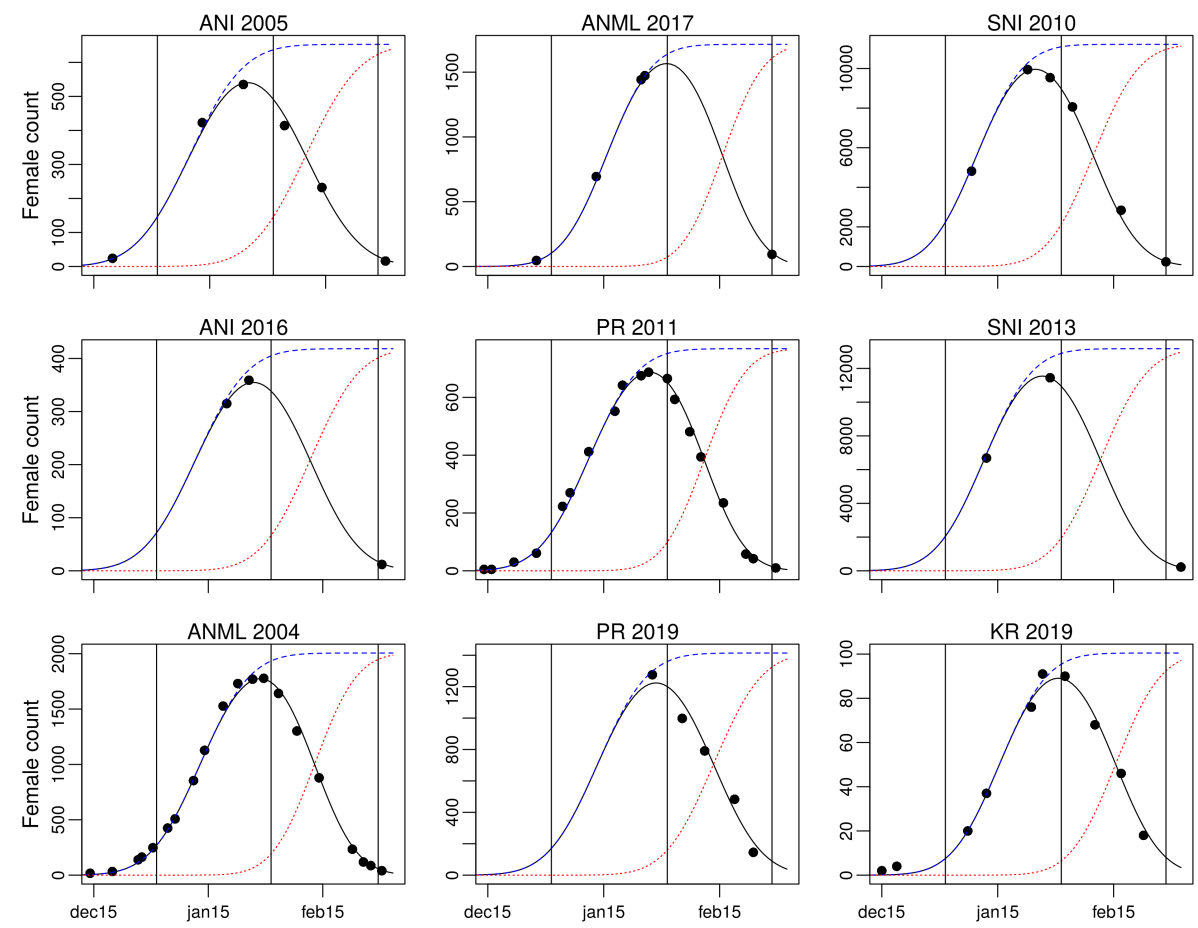

Table 1. Six parameters for the census model in a single year and their hyper-parameters across years. The six main parameters are subscripted since there is one for every year $i$. The population size had no hyper-parameters, meaning every year's population was independent, and the two parameters describing tenure had hyper-parameters fixed in advance as narrow priors $\left(\mu_{d}=31.06, \sigma_{d}=0.27, \mu_{v}=0.1212, \sigma_{v}=0.0062\right)$, a requirement for fitting the model [5]]. The remaining parameters had Gaussian hyper-distributions estimated from the data. In a model covering 20 years of censuses, 126 parameters are needed: 120 main parameters (6 per year) plus 6 hyper-parameters.

\begin{tabular}{|l|c|c|c|}
\hline & & \multicolumn{2}{|c|}{ Hyper-parameter } \\
Parameter & Annual & Mean & SD \\
\hline Female population & $N_{i}$ & none & none \\
Mean arrival date & $\hat{a}_{i}$ & $\mu_{a}$ & $\sigma_{a}$ \\
SD arrival date & $s_{i}$ & $\mu_{s}$ & $\sigma_{s}$ \\
Correlation arrival-tenure & $c_{i}$ & $\mu_{c}$ & $\sigma_{c}$ \\
Mean tenure on colony (Prior) & $\hat{d}_{i}$ & $\mu_{d}$ & $\sigma_{d}$ \\
CV tenure (Prior) & $v_{i}$ & $\mu_{v}$ & $\sigma_{v}$ \\
\hline
\end{tabular}

\section{The correction factor}

Consider site $s$ in year $i$ and define $N_{i s}$ as the total number of breeding females using the site that season. $C_{i s}(t)$ is the estimated census curve at site $s$ in year $i$, the number 
of females on the colony on each day $t$ (Eq1, Fig 2). Then $C_{i s}(t) / N_{i s}$ is the proportion of females on the colony on day $t$. The inverse of the proportion is the correction factor: a multiplier for a female count on day $t$ that yields the total female population,

$$
m_{i s}(t)=\frac{N_{i s}}{C_{i s}(t)} .
$$

The correction factor is calculated separately in every year at a site, but to be useful in future years, we need the average across all years for site $s, \widehat{m}_{i s}(t)$. To generate $\widehat{m}_{i s}(t)$, census curves for each site $s$ were simulated using many parameter combinations from the posterior distributions of the model parameters at that site; each simulation produced one $m_{s}(t)$, a multiplier for each day $t$ at site $s$. To capture the total error associated with a multiplier, we incorporated both year-to-year variation and within-year error. For the former, we sampled 30 years at random from each site, and for the latter, made 40 random draws from the parameters' posterior distributions within each year; the mean and $95 \%$ quantiles of those 1200 simulations yield $\widehat{m}_{i s}(t)$. To be most relevant for the present, years were chosen from 2002-2018 at Año Nuevo Island, Año Nuevo Mainland, and Point Reyes. This was a period in which censuses and the model fit were consistent and reliable. There were only four years available at the Channel Islands and three at King Range, so all were utilized.

\section{Results}

\section{Census timing}

Fitted censuses and observed counts followed a similar bell-shaped curve from late December to early March at all sites (Fig 2). Comparison of arrival date and peak census date across years and across sites demonstrates the consistency (Fig 3). In early years at Año Nuevo Mainland the arrival dates were around 17 Jan, but were consistently near 14 Jan after 1990. Point Reyes and Año Nuevo Island also advanced by 3-4 days in early years then stabilized (Fig $3 \mathrm{~A}$ ). Between colonies, the long-term mean arrival date (the hyper-mean across years, $\mu_{a}$ ) varied by 4.6 days: 10 Jan at the Channel Islands, 11 Jan at Año Nuevo Island, 14 Jan at Point Reyes, and 15 Jan at Año Nuevo Mainland and King Range (Fig $3 \mathrm{~A}$ ). The date of the peak census was 15-17 days after mean arrival: 25 Jan at the Channel Islands, 26 Jan at Año Nuevo Island, 28 Jan at Point Reyes, 30 Jan at King Range, and 31 Jan at Año Nuevo Mainland. Variation in the peak mirrored variation in arrival (Fig $3 \mathrm{~B})$.

There were year-to-year fluctuations, however, mostly by $<2$ days but with a few outliers (Fig 3). Some of the outliers were associated with unusual events. At Año Nuevo, 1983 had an enormous storm on 27 Jan, and surf covered the island beach. Most late arriving females used the mainland, creating early arrival on the island and late on the mainland [[14]]. Again in 2010 at Año Nuevo and in 1995, 1998, and 2010 at Point Reyes, large storm surf forced females to move around, some to other colonies, thus creating unusual census patterns [[15] . Other outliers were associated with poor census coverage, for example in 1998-2000 at Año Nuevo [[5] ]. On the other hand, there was a steady delay in arrival over 2010-2015, consistent at four sites, supported by thorough census data and not associated with major storms. At the Channel Islands and King Range, the few years of data were consistent, but credible intervals were wide due to small samples (Figs 3). 
Figure 3. Variation in census timing. A) Mean annual arrival date, $\hat{a}_{i}$, and B) date of peak female census, both estimated from census model. Three curves are colonies with long time series (ANI: Año Nuevo Island; ANML: Año Nuevo Mainland; PR: Point Reyes); the four green points are individual years from the Channel Islands (CI), and the three gray points from King Range (KR). Dashed vertical lines show 95\% credible intervals in each year. At the far right, open circles and solid lines show the hyper-means (long-term means) and credible intervals for all sites.
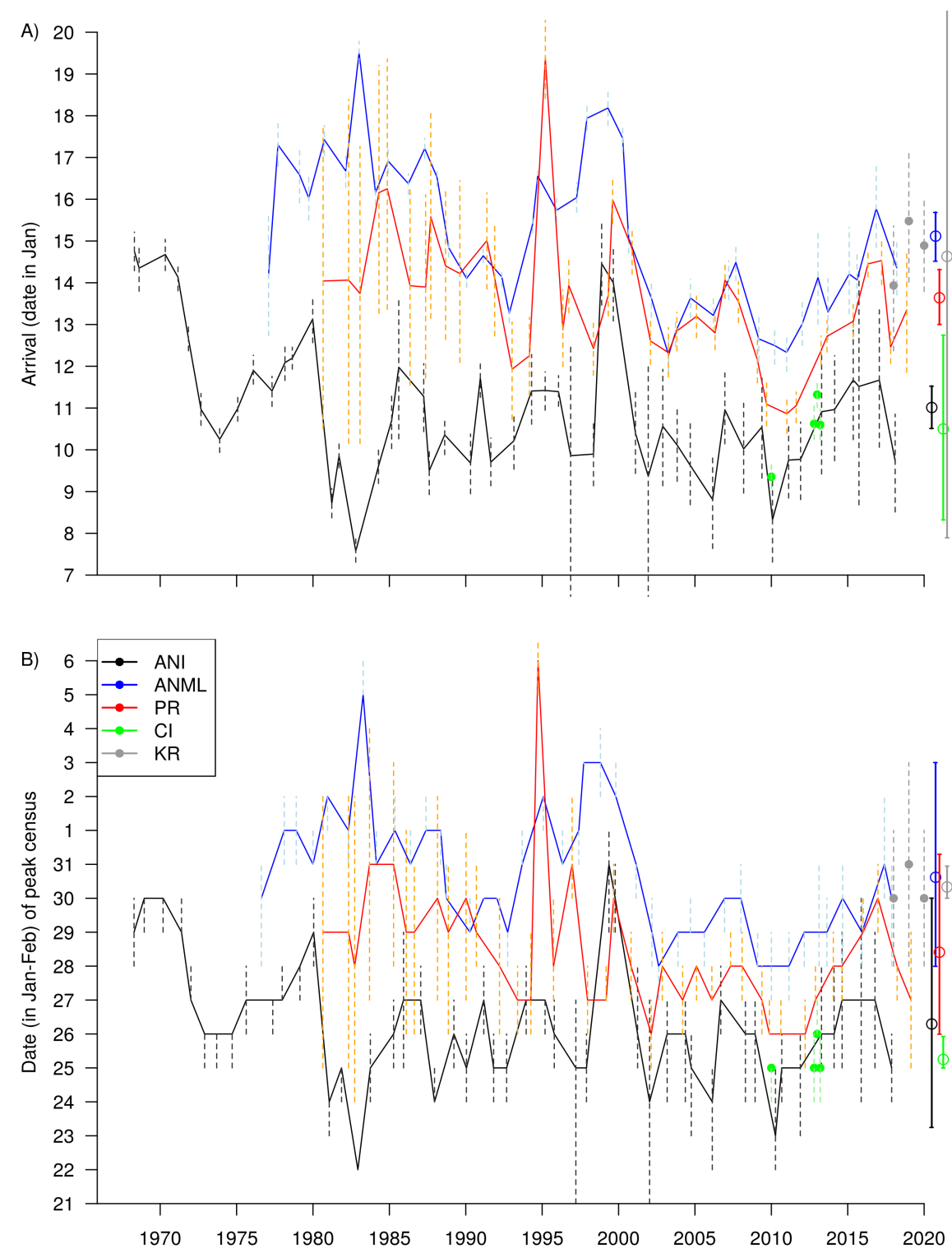

\section{Correction factors for single counts}

Similarity in the shape and timing of the census curves at all sites meant similar correction factors (Fig 4). Using a female count at the peak of the census curve, the correction for yielding total population size, $N_{i}$, was 1.13 at Año Nuevo Mainland, King Range, and the Channel Islands, 1.15 at Point Reyes, and 1.17 at Año Nuevo Island (Appendix Tables A1-A5). A count at the peak had the narrowest credible intervals. Within \pm 2 days of the peak, correction factors and credible intervals barely changed, 
but beyond \pm 5 days, they increased rapidly (Fig 4). The correction curve was early at Año Nuevo Island and the Channel Islands compared to the other three locations, corresponding to differences in female arrival and thus census timing. Nevertheless, at all five sites on 26-28 Jan, correction curves were close together, and the multiplier was between 1.13 and 1.19 (Fig 4 ).

Figure 4. Correction factors. The model's estimated multiplier for converting any daily count into a total female population, as a function of date (ANI = Año Nuevo Island, Channel Islands, ANML=Año Nuevo Mainland, Point Reyes). Each panel shows the curve for one of those four sites highlighted in blue, including credible intervals; the red lines are the remaining sites, with King Range added in green in all panels. Dotted horizontal guide lines are at 1.1 and 1.2. The census and hence the correction curve was earlier at Año Nuevo Island and the Channel Islands, later at the other three sites.
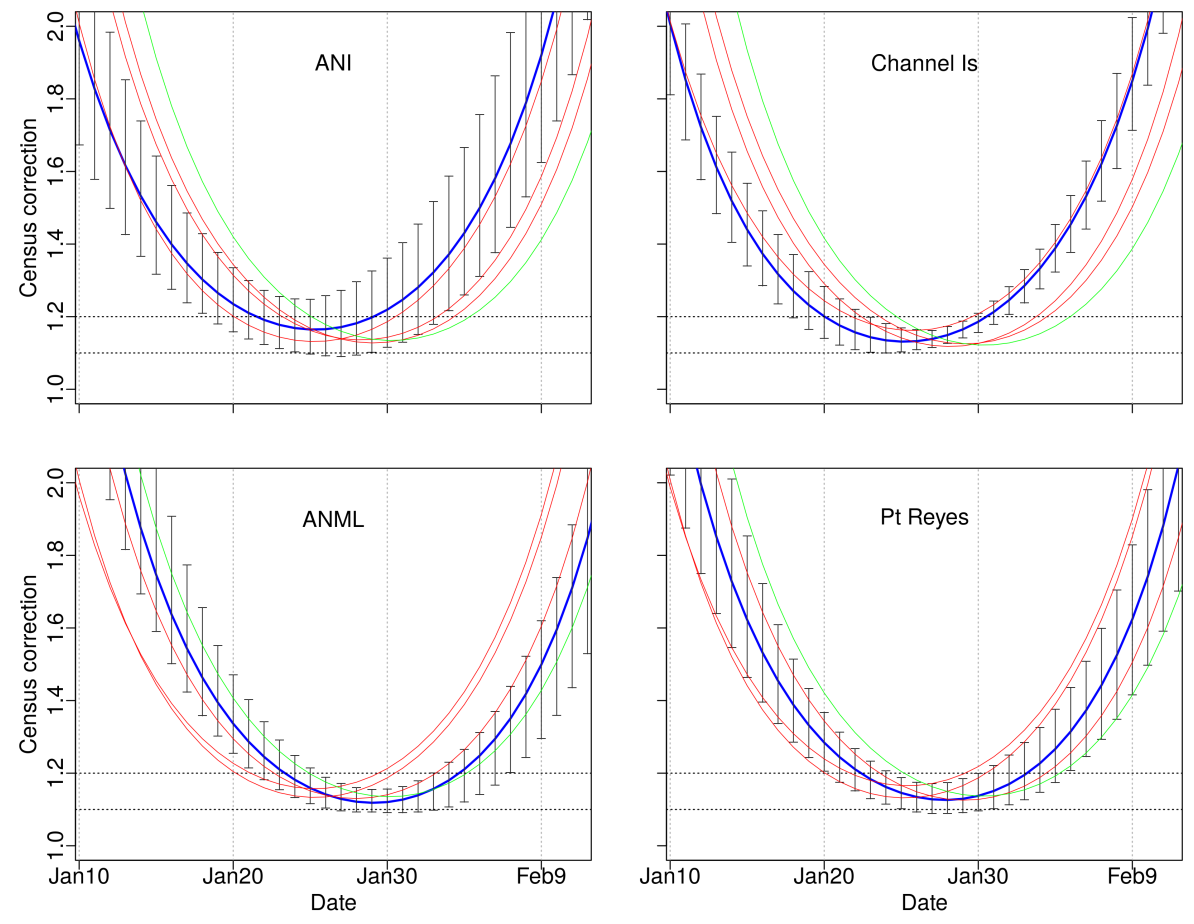

\section{Discussion}

Over 50 years at Año Nuevo Island, the timing of the census curve has changed little. It was 4-5 days earlier than it is presently during early years, a pattern that repeated at Año Nuevo Mainland and Point Reyes, but after 1990 the census peak has been within 2 days of a long-term average in most years. The late census date in newly founded colonies is a consequence of dispersal behavior of immigrant females. At high-density colonies, the animals most likely to emigrate to new colonies are young females arriving late at a an existing colony, when density is high [[16. 17]]. This was conspicuous in 1983 at Año Nuevo, for example, when storms drove the latest females to the mainland [14]], and also at Point Reyes, which was established when the nearby Farallon Island colony was awash with storm surge [[18]]. In the closely related southern elephant seal, the peak of the female census curve is likewise consistent across colonies at the core of the latitudinal range [[4]], but the outlying Peninsula Valdes colony, well to the north, was 10 days earlier [[19]]. 
Consistency across sites produces consistent daily correction factors. At all sites we studied, the smallest error bars in corrections were between 23 and 30 Jan. Long-term consistency at Point Reyes and Año Nuevo suggests that the same week will continue to be optimal in the future. At the Channel Islands and King Range, where we do not have long time series, we cannot assess consistency, but for the present we assume it holds. Though colonies differed slightly in timing, the flat bottom of the correction curve leads us to suggest that 26-28 Jan is the best day for a single count at these locations and an optimal choice for counting other colonies not yet analyzed. Over those days, the correction factor was 1.13-1.19, and credible intervals mostly 1.1-1.2 (but as high as 1.3 at Año Nuevo Island). A count between 26 and 28 Jan thus produces a population estimate within $10 \%$ error, excellent precision for estimating population size of a highly pelagic marine predator.

The colonies we examined varied greatly in size. The Channel Islands each had over 10,000 females spread across many beaches, but at Año Nuevo, we separated the single beach on the island from several nearby mainland groups, and the King Range colony had only 100 animals. Despite these differences, the correction factors barely differed. We conclude that a population of breeding elephant seals can be estimated effectively from just one count, whether a single isolated group or a large number of groups counted together.

Correction factors are often applied to censuses of marine mammals because direct counts miss animals [ [ [20 23] $]$. In typical examples, animals come and go over a few hours, or sometimes days, and correction factors are strictly empirical. The case of elephant seals, with a very regular breeding haul-out, is the only one we know based on a quantitative description of behavior [ 3.5$]$.

A further approach at a novel location would be to use a few counts in the second half of January to establish the timing of the census and indicate which of the correction factors to use. Alternatively, if the observed peak count fell far outside 25-31 Jan, more work would be required to generate good estimators. It remains to be seen how closely the census timing holds at more distant colonies, such as those in Mexico [[24]], which are five degrees latitude further south. In southern elephant seals, that is far enough for census timing to differ by 10 days [19]]. Once Mexican colonies are added to these analyses, the entire range of northern elephant seals - six sites in the United States and two in Mexico - would be covered [6, 25]]. It would then be routinely possible, with single counts at eight colonies, to monitor the entire world population of a deep-ocean predator.

\section{Acknowledgments}

We thank Marshall Sylvan, who stated then solved this problem in the 1970s at Año Nuevo Island. We also thank numerous scientists for field work and advice, especially J. Reiter, G. Oliver, R. Gisiner, M. O. Pierson, D. Adams, J. Longstreth, D. Notthelfer, J. Pettee, D. Press, S. Waber, S. Van Der Wal, B. Becker, M. Cox, J. Irwin, J. McAbery, P. Ruiz-Lopez, R. Hein, P. Forman, C. Nasr, and E. Levy. The National Science Foundation, Office of Naval Research, Bureau of Land Management, National Geographic Society, Año Nuevo State Park, National Park Service, San Francisco Bay Area Network Inventory and Monitoring Program, Point Blue Conservation Science (formerly Point Reyes Bird Observatory), and Point Reyes National Seashore provided financial support; the Institute of Marine Sciences and the University of California, Santa Cruz, supported field work at Año Nuevo. Seal observations were authorized under permits 939, 373-1575, 373-1868-00, 17152-00, 2142514535, 14636, and 21425 from the National Marine Fisheries Service as well as numerous earlier permits. 


\section{References}

1. Le Boeuf BJ, Laws RM, editors. Elephant Seals: Population Ecology, Behavior, and Physiology. University of California Press; 1994.

2. Le Boeuf BJ, Condit R, Morris PA, Reiter J. The northern elephant seal rookery at Año Nuevo: a case study in colonization. Aquatic Mammals. 2011;37:486-501. doi:10.1578/AM.37.4.2011.486.

3. Rothery P, McCann TS. Estimating pup production in elephant seals at South Georgia. Mammal Population Studies. 1987; p. 211-223.

4. Galimberti F, Sanvito S. Modeling female haul-out in southern elephant seals (Mirounga leonina). Aquatic Mammals. 2001;27:92-104.

5. Condit R, Le Boeuf BJ, Morris PA, Sylvan M. Estimating population size in asynchronous aggregations: a Bayesian approach and test with elephant seal censuses. Marine Mammal Science. 2007;23(4):834-855.

6. Lowry MS, Condit R, Hatfield B, Allen SG, Berger R, Laake J, et al. Abundance, distribution, and growth of the northern elephant seal, Mirounga angustirostris, in the United States in 2010. Aquatic Mammals. 2014;40(1):20-31. doi:10.1578/AM.40.1.2014.20.

7. Adams D, Press D, Hester M, Nevins H, Roberts D, Becker B, et al. San Francisco Bay Area Network pinniped monitoring protocol. National Park Service; 2009. NPS/SFAN/NRR - 2009/170.

8. Goley PD. Emerging elephant seal colony in the BLM King Range Conservation Area, California. Bureau of Land Management; 2020.

9. Lowry MS, L PW, Lynn MS, Westlake RL, Julian F. Counts of northern elephant seals, Mirounga angustirostris, from large-format aerial photographs taken at rookeries in southern California during the breeding season. Fishery Bulletin. 1996;94:176-185.

10. Lowry MS. Counts of northern elephant seals at rookeries in the Southern California Bight: 1981-2001. National Marine Fisheries Service; 2002. NOAA-TM-NMFS-SWFSC-345.

11. Gelman A, Hill J. Data Analysis Using Regression and Multilevel-Hierarchical Models. Cambridge University Press; 2007.

12. Condit R, Ashton P, Bunyavejchewin S, Dattaraja HS, Davies S, Esufali S, et al. The importance of demographic niches to tree diversity. Science. 2006;313(5783):98-101.

13. Condit R, Reiter J, Morris PA, Berger R, Allen SG, Le Boeuf BJ. Lifetime survival and senescence of northern elephant seals, Mirounga angustirostris. Marine Mammal Science. 2014;30(1):122-138. doi:10.1111/mms.12025.

14. Le Boeuf BJ, Condit R. The high cost of living on the beach. Pacific Discovery. 1983; p. $12-14$.

15. Pettee JC. Factors affecting distribution and reproductive success in elephant seals (Mirounga angustirostris) at Point Reyes. San Francisco State University; 1999. 
16. Le Boeuf BJ, Ainley DG, Lewis TJ. Elephant seals on the Farallones: population structure of an incipient breeding colony. Journal of Mammalogy. $1974 ; 55: 370-385$.

17. Le Boeuf BJ, Panken KJ. Elephant seals breeding on the mainland in California. Proceedings of the California Academy of Sciences. 1977;41:267-280.

18. Sydeman WJ, Allen SG. Pinnipeds in the Gulf of the Farallones; 25 years of monitoring. Marine Mammal Science. 1999;15:446-461.

19. Campagna C, Lewis M, Baldi R. Breeding biology of southern elephant seals in Patagonia. Marine Mammal Science. 1993;9(1):34-47. doi:10.1111/j.1748-7692.1993.tb00424.x.

20. Erickson AW, Bledsoe LJ, Hanson MB. Bootstrap correction for diurnal activity cycle in census data for antarctic seals. Marine Mammal Science. 1989;5(1):29-56. doi:10.1111/j.1748-7692.1989.tb00212.x.

21. Thompson PM, Harwood J. Methods for estimating the population size of common seals, Phoca vitulina. Journal of Applied Ecology. 1990;27(3):924-938.

22. Edwards HH, Pollock KH, Ackerman BB, Reynolds JE, Powell JA. Estimation of detection probability in manatee aerial surveys at a winter aggregation site. Journal of Wildlife Management. 2007;71(6):2052-2060. doi:10.2193/2005-645.

23. Harvey JT, Goley D. Determining a correction factor for aerial surveys of harbor seals in California. Marine Mammal Science. 2011;27(4):719-735. doi:10.1111/j.1748-7692.2010.00446.x.

24. García-Aguilar MC. Breeding biology of the northern elephant seal (Mirounga angustrirostris) at the Isla San Benito del Oeste, Eastern Pacific, Mexico. Aquatic Mammals. 2004;30:289-295.

25. Stewart BS, Yochem PK, Le Boeuf BJ, Huber HR, DeLong RL, Jameson RJ, et al. Population recovery and status of the northern elephant seal, Mirounga angustirostris. In: Le Boeuf BJ, Laws RM, editors. Elephant Seals: Population Ecology, Behavior, and Physiology. University of California Press; 1994. p. 29-48. 


\section{Appendices}

Correction factors for single counts of breeding female elephant seals between 11 Jan and $8 \mathrm{Feb}$ at five locations (the Channel Island location includes three colonies combined). The total number of females over the entire season can be calculated by multiplying a single count on a specified day by the Multiplier listed. Credible intervals (95\%) for the estimated total number are derived from the columns Lower and Upper. The correction factors are given separately for the five different sites modeled in the main text: Año Nuevo Island (Table A1), Año Nuevo Mainland (Table A2), Point Reyes (Table A3), Channel Islands (Table A4), and King Range (Table A5). In addition, because two sections of the mainland colony at Año Nuevo Mainland are often counted separately, a South Point and a North Point, those corrections are also included (Tables A6, A7). Timing of the census at the three sections of Año Nuevo are shown in Figs S1, S2 
Table A1. Correction factors for converting observed daily counts of female elephant seals during the breeding season into the total female population at Año Nuevo Island. The total population using the colony in a year is estimated by multiplying a count on any of the dates by the given Multiplier. Lower and upper credible intervals (95\%) are derived using the columns Lower and Upper.

\begin{tabular}{lccc} 
Date & Multiplier & Lower & Upper \\
\hline Jan11 & 1.859 & 1.583 & 2.198 \\
Jan12 & 1.741 & 1.500 & 2.047 \\
Jan13 & 1.639 & 1.431 & 1.910 \\
Jan14 & 1.552 & 1.370 & 1.795 \\
Jan15 & 1.477 & 1.318 & 1.690 \\
Jan16 & 1.413 & 1.273 & 1.600 \\
Jan17 & 1.359 & 1.235 & 1.528 \\
Jan18 & 1.313 & 1.205 & 1.464 \\
Jan19 & 1.275 & 1.182 & 1.409 \\
Jan20 & 1.243 & 1.160 & 1.362 \\
Jan21 & 1.218 & 1.141 & 1.323 \\
Jan22 & 1.198 & 1.125 & 1.293 \\
Jan23 & 1.184 & 1.114 & 1.270 \\
Jan24 & 1.174 & 1.106 & 1.253 \\
Jan25 & 1.170 & 1.102 & 1.246 \\
Jan26 & 1.171 & 1.101 & 1.250 \\
Jan27 & 1.176 & 1.104 & 1.261 \\
Jan28 & 1.186 & 1.108 & 1.278 \\
Jan29 & 1.202 & 1.118 & 1.306 \\
Jan30 & 1.223 & 1.129 & 1.342 \\
Jan31 & 1.250 & 1.148 & 1.385 \\
Feb1 & 1.283 & 1.169 & 1.434 \\
Feb2 & 1.323 & 1.199 & 1.493 \\
Feb3 & 1.372 & 1.231 & 1.563 \\
Feb4 & 1.428 & 1.274 & 1.638 \\
Feb5 & 1.495 & 1.321 & 1.732 \\
Feb6 & 1.574 & 1.377 & 1.835 \\
Feb7 & 1.665 & 1.439 & 1.954 \\
Feb8 & 1.772 & 1.516 & 2.091 \\
\hline & & & \\
\hline & & &
\end{tabular}


Table A2. Correction factors for converting observed daily counts of female elephant seals during the breeding season into the total female population at Año Nuevo Mainland. The total population using the colony in a year is estimated by multiplying a count on any of the dates by the given Multiplier. Lower and upper credible intervals (95\%) are derived using the columns Lower and Upper.

\begin{tabular}{lccc} 
Date & Multiplier & Lower & Upper \\
\hline Jan11 & 2.444 & 2.097 & 2.970 \\
Jan12 & 2.234 & 1.937 & 2.646 \\
Jan13 & 2.056 & 1.801 & 2.383 \\
Jan14 & 1.904 & 1.685 & 2.175 \\
Jan15 & 1.773 & 1.584 & 2.008 \\
Jan16 & 1.662 & 1.498 & 1.866 \\
Jan17 & 1.566 & 1.424 & 1.735 \\
Jan18 & 1.485 & 1.361 & 1.634 \\
Jan19 & 1.415 & 1.308 & 1.546 \\
Jan20 & 1.355 & 1.263 & 1.469 \\
Jan21 & 1.304 & 1.225 & 1.402 \\
Jan22 & 1.261 & 1.193 & 1.349 \\
Jan23 & 1.225 & 1.167 & 1.308 \\
Jan24 & 1.196 & 1.147 & 1.271 \\
Jan25 & 1.172 & 1.132 & 1.240 \\
Jan26 & 1.154 & 1.121 & 1.216 \\
Jan27 & 1.140 & 1.112 & 1.198 \\
Jan28 & 1.132 & 1.104 & 1.184 \\
Jan29 & 1.129 & 1.098 & 1.178 \\
Jan30 & 1.130 & 1.095 & 1.178 \\
Jan31 & 1.136 & 1.097 & 1.184 \\
Feb1 & 1.147 & 1.100 & 1.196 \\
Feb2 & 1.164 & 1.108 & 1.214 \\
Feb3 & 1.187 & 1.120 & 1.243 \\
Feb4 & 1.216 & 1.138 & 1.280 \\
Feb5 & 1.252 & 1.162 & 1.329 \\
Feb6 & 1.297 & 1.193 & 1.388 \\
Feb7 & 1.350 & 1.233 & 1.457 \\
Feb8 & 1.414 & 1.280 & 1.540 \\
\hline & & & \\
\hline & & &
\end{tabular}


Table A3. Correction factors for converting observed daily counts of female elephant seals during the breeding season into the total female population at Point Reyes. The total population using the colony in a year is estimated by multiplying a count on any of the dates by the given Multiplier. Lower and upper credible intervals (95\%) are derived using the columns Lower and Upper.

\begin{tabular}{lccc} 
Date & Multiplier & Lower & Upper \\
\hline Jan11 & 2.295 & 1.888 & 2.678 \\
Jan12 & 2.107 & 1.762 & 2.427 \\
Jan13 & 1.946 & 1.650 & 2.222 \\
Jan14 & 1.810 & 1.555 & 2.056 \\
Jan15 & 1.693 & 1.472 & 1.916 \\
Jan16 & 1.593 & 1.401 & 1.797 \\
Jan17 & 1.507 & 1.340 & 1.696 \\
Jan18 & 1.434 & 1.290 & 1.606 \\
Jan19 & 1.372 & 1.246 & 1.528 \\
Jan20 & 1.319 & 1.210 & 1.463 \\
Jan21 & 1.274 & 1.179 & 1.406 \\
Jan22 & 1.236 & 1.154 & 1.357 \\
Jan23 & 1.206 & 1.133 & 1.316 \\
Jan24 & 1.181 & 1.116 & 1.283 \\
Jan25 & 1.161 & 1.104 & 1.254 \\
Jan26 & 1.147 & 1.096 & 1.230 \\
Jan27 & 1.138 & 1.091 & 1.213 \\
Jan28 & 1.133 & 1.089 & 1.203 \\
Jan29 & 1.134 & 1.087 & 1.200 \\
Jan30 & 1.139 & 1.088 & 1.207 \\
Jan31 & 1.149 & 1.093 & 1.225 \\
Feb1 & 1.165 & 1.102 & 1.253 \\
Feb2 & 1.186 & 1.115 & 1.287 \\
Feb3 & 1.214 & 1.134 & 1.328 \\
Feb4 & 1.249 & 1.159 & 1.378 \\
Feb5 & 1.292 & 1.190 & 1.437 \\
Feb6 & 1.343 & 1.228 & 1.513 \\
Feb7 & 1.405 & 1.276 & 1.597 \\
Feb8 & 1.479 & 1.333 & 1.702 \\
\hline & & & \\
\hline & & &
\end{tabular}


Table A4. Correction factors for converting observed daily counts of female elephant seals during the breeding season into the total female population at Channel Islands. The total population using the colony in a year is estimated by multiplying a count on any of the dates by the given Multiplier. Lower and upper credible intervals (95\%) are derived using the columns Lower and Upper.

\begin{tabular}{lccc} 
Date & Multiplier & Lower & Upper \\
\hline Jan11 & 1.854 & 1.685 & 2.007 \\
Jan12 & 1.723 & 1.579 & 1.869 \\
Jan13 & 1.613 & 1.488 & 1.747 \\
Jan14 & 1.519 & 1.411 & 1.645 \\
Jan15 & 1.440 & 1.343 & 1.558 \\
Jan16 & 1.374 & 1.279 & 1.483 \\
Jan17 & 1.318 & 1.231 & 1.418 \\
Jan18 & 1.271 & 1.190 & 1.362 \\
Jan19 & 1.232 & 1.158 & 1.315 \\
Jan20 & 1.201 & 1.134 & 1.277 \\
Jan21 & 1.176 & 1.118 & 1.246 \\
Jan22 & 1.157 & 1.107 & 1.220 \\
Jan23 & 1.143 & 1.101 & 1.198 \\
Jan24 & 1.135 & 1.097 & 1.183 \\
Jan25 & 1.131 & 1.099 & 1.176 \\
Jan26 & 1.133 & 1.104 & 1.172 \\
Jan27 & 1.138 & 1.117 & 1.172 \\
Jan28 & 1.149 & 1.128 & 1.177 \\
Jan29 & 1.165 & 1.140 & 1.188 \\
Jan30 & 1.186 & 1.157 & 1.213 \\
Jan31 & 1.213 & 1.177 & 1.244 \\
Feb1 & 1.246 & 1.201 & 1.284 \\
Feb2 & 1.286 & 1.231 & 1.332 \\
Feb3 & 1.333 & 1.268 & 1.388 \\
Feb4 & 1.389 & 1.314 & 1.455 \\
Feb5 & 1.455 & 1.369 & 1.534 \\
Feb6 & 1.532 & 1.434 & 1.628 \\
Feb7 & 1.622 & 1.510 & 1.737 \\
Feb8 & 1.727 & 1.599 & 1.865 \\
\hline & & & \\
\hline & & &
\end{tabular}


Table A5. Correction factors for converting observed daily counts of female elephant seals during the breeding season into the total female population at King Range. The total population using the colony in a year is estimated by multiplying a count on any of the dates by the given Multiplier. Lower and upper credible intervals (95\%) are derived using the columns Lower and Upper.

\begin{tabular}{lccc} 
Date & Multiplier & Lower & Upper \\
\hline Jan11 & 2.771 & 2.236 & 3.372 \\
Jan12 & 2.506 & 2.079 & 3.001 \\
Jan13 & 2.283 & 1.940 & 2.698 \\
Jan14 & 2.095 & 1.820 & 2.441 \\
Jan15 & 1.935 & 1.709 & 2.247 \\
Jan16 & 1.800 & 1.606 & 2.079 \\
Jan17 & 1.684 & 1.508 & 1.937 \\
Jan18 & 1.585 & 1.422 & 1.814 \\
Jan19 & 1.501 & 1.348 & 1.708 \\
Jan20 & 1.429 & 1.287 & 1.617 \\
Jan21 & 1.367 & 1.233 & 1.539 \\
Jan22 & 1.315 & 1.193 & 1.468 \\
Jan23 & 1.271 & 1.159 & 1.414 \\
Jan24 & 1.234 & 1.131 & 1.367 \\
Jan25 & 1.204 & 1.109 & 1.329 \\
Jan26 & 1.180 & 1.092 & 1.298 \\
Jan27 & 1.161 & 1.080 & 1.272 \\
Jan28 & 1.147 & 1.071 & 1.254 \\
Jan29 & 1.138 & 1.067 & 1.240 \\
Jan30 & 1.133 & 1.062 & 1.233 \\
Jan31 & 1.134 & 1.062 & 1.234 \\
Feb1 & 1.139 & 1.064 & 1.241 \\
Feb2 & 1.149 & 1.069 & 1.259 \\
Feb3 & 1.164 & 1.078 & 1.284 \\
Feb4 & 1.185 & 1.090 & 1.314 \\
Feb5 & 1.212 & 1.105 & 1.353 \\
Feb6 & 1.245 & 1.126 & 1.399 \\
Feb7 & 1.287 & 1.152 & 1.460 \\
Feb8 & 1.338 & 1.182 & 1.529 \\
\hline & & & \\
\hline & & &
\end{tabular}


Table A6. Correction factors for converting observed daily counts of female elephant seals during the breeding season into the total female population at Año Nuevo Mainland South. The total population using the colony in a year is estimated by multiplying a count on any of the dates by the given Multiplier. Lower and upper credible intervals (95\%) are derived using the columns Lower and Upper.

\begin{tabular}{lccc} 
Date & Multiplier & Lower & Upper \\
\hline Jan11 & 2.461 & 2.136 & 2.922 \\
Jan12 & 2.248 & 1.976 & 2.622 \\
Jan13 & 2.066 & 1.837 & 2.374 \\
Jan14 & 1.912 & 1.718 & 2.164 \\
Jan15 & 1.780 & 1.618 & 1.993 \\
Jan16 & 1.667 & 1.526 & 1.849 \\
Jan17 & 1.571 & 1.450 & 1.720 \\
Jan18 & 1.488 & 1.383 & 1.614 \\
Jan19 & 1.417 & 1.327 & 1.527 \\
Jan20 & 1.357 & 1.279 & 1.447 \\
Jan21 & 1.305 & 1.238 & 1.381 \\
Jan22 & 1.262 & 1.203 & 1.326 \\
Jan23 & 1.225 & 1.174 & 1.281 \\
Jan24 & 1.195 & 1.151 & 1.246 \\
Jan25 & 1.171 & 1.133 & 1.217 \\
Jan26 & 1.152 & 1.117 & 1.195 \\
Jan27 & 1.139 & 1.104 & 1.177 \\
Jan28 & 1.130 & 1.095 & 1.166 \\
Jan29 & 1.126 & 1.091 & 1.162 \\
Jan30 & 1.127 & 1.089 & 1.166 \\
Jan31 & 1.132 & 1.092 & 1.177 \\
Feb1 & 1.143 & 1.098 & 1.197 \\
Feb2 & 1.159 & 1.109 & 1.220 \\
Feb3 & 1.182 & 1.123 & 1.250 \\
Feb4 & 1.210 & 1.144 & 1.287 \\
Feb5 & 1.246 & 1.169 & 1.333 \\
Feb6 & 1.290 & 1.200 & 1.388 \\
Feb7 & 1.343 & 1.239 & 1.453 \\
Feb8 & 1.407 & 1.285 & 1.533 \\
\hline & & & \\
\hline & & &
\end{tabular}


Table A7. Correction factors for converting observed daily counts of female elephant seals during the breeding season into the total female population at Año Nuevo Mainland North. The total population using the colony in a year is estimated by multiplying a count on any of the dates by the given Multiplier. Lower and upper credible intervals (95\%) are derived using the columns Lower and Upper.

\begin{tabular}{lccc} 
Date & Multiplier & Lower & Upper \\
\hline Jan11 & 2.286 & 1.526 & 3.313 \\
Jan12 & 2.078 & 1.430 & 2.921 \\
Jan13 & 1.905 & 1.346 & 2.596 \\
Jan14 & 1.760 & 1.276 & 2.332 \\
Jan15 & 1.639 & 1.221 & 2.112 \\
Jan16 & 1.538 & 1.178 & 1.926 \\
Jan17 & 1.453 & 1.144 & 1.771 \\
Jan18 & 1.382 & 1.117 & 1.641 \\
Jan19 & 1.322 & 1.097 & 1.535 \\
Jan20 & 1.273 & 1.086 & 1.446 \\
Jan21 & 1.233 & 1.080 & 1.375 \\
Jan22 & 1.200 & 1.075 & 1.327 \\
Jan23 & 1.174 & 1.076 & 1.290 \\
Jan24 & 1.154 & 1.080 & 1.277 \\
Jan25 & 1.140 & 1.078 & 1.273 \\
Jan26 & 1.130 & 1.067 & 1.276 \\
Jan27 & 1.126 & 1.054 & 1.282 \\
Jan28 & 1.126 & 1.045 & 1.295 \\
Jan29 & 1.131 & 1.039 & 1.312 \\
Jan30 & 1.141 & 1.035 & 1.334 \\
Jan31 & 1.155 & 1.036 & 1.365 \\
Feb1 & 1.175 & 1.039 & 1.398 \\
Feb2 & 1.201 & 1.046 & 1.439 \\
Feb3 & 1.232 & 1.057 & 1.489 \\
Feb4 & 1.271 & 1.072 & 1.556 \\
Feb5 & 1.318 & 1.093 & 1.631 \\
Feb6 & 1.374 & 1.118 & 1.727 \\
Feb7 & 1.441 & 1.150 & 1.845 \\
Feb8 & 1.521 & 1.189 & 1.989 \\
\hline & & & \\
\hline & & &
\end{tabular}


Figure S1. Arrival date at Año Nuevo. Arrival date at three Año Nuevo subcolonies as estimated from the census model (ANI: Año Nuevo Island; ANSP: Año Nuevo south point); ANNP: Año Nuevo main point). Dashed vertical lines show $95 \%$ credible intervals in each year. At the far right, open circles and solid lines show the overall mean (all years combined) at all three subcolonies. See Fig 3 A.

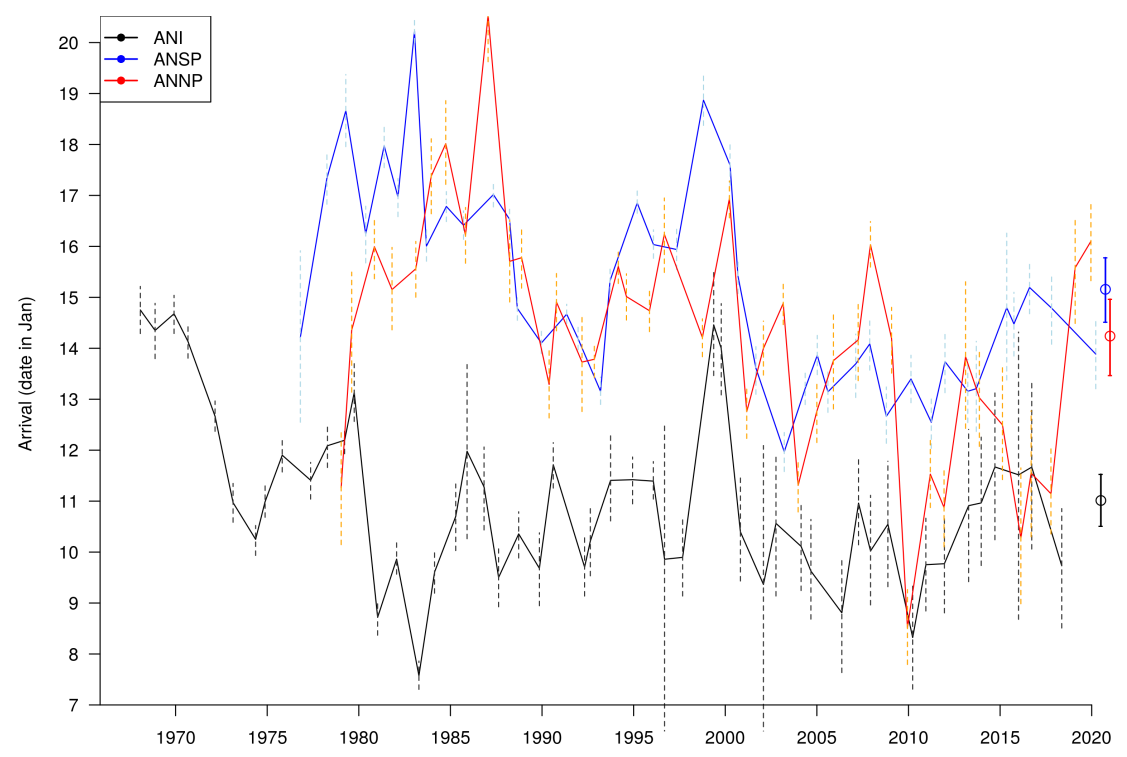


Figure S2. Date of peak census at Año Nuevo. Peak female count at three Año Nuevo subcolonies as estimated from the census model comparing three subcolonies at Año Nuevo(ANI: Año Nuevo Island; ANSP: Año Nuevo south point); ANNP: Año Nuevo main point). Dashed vertical lines show $95 \%$ credible intervals in each year. At the far right, open circles and solid lines show the overall mean (all years combined) at all three subcolonies. See Fig 3 B.

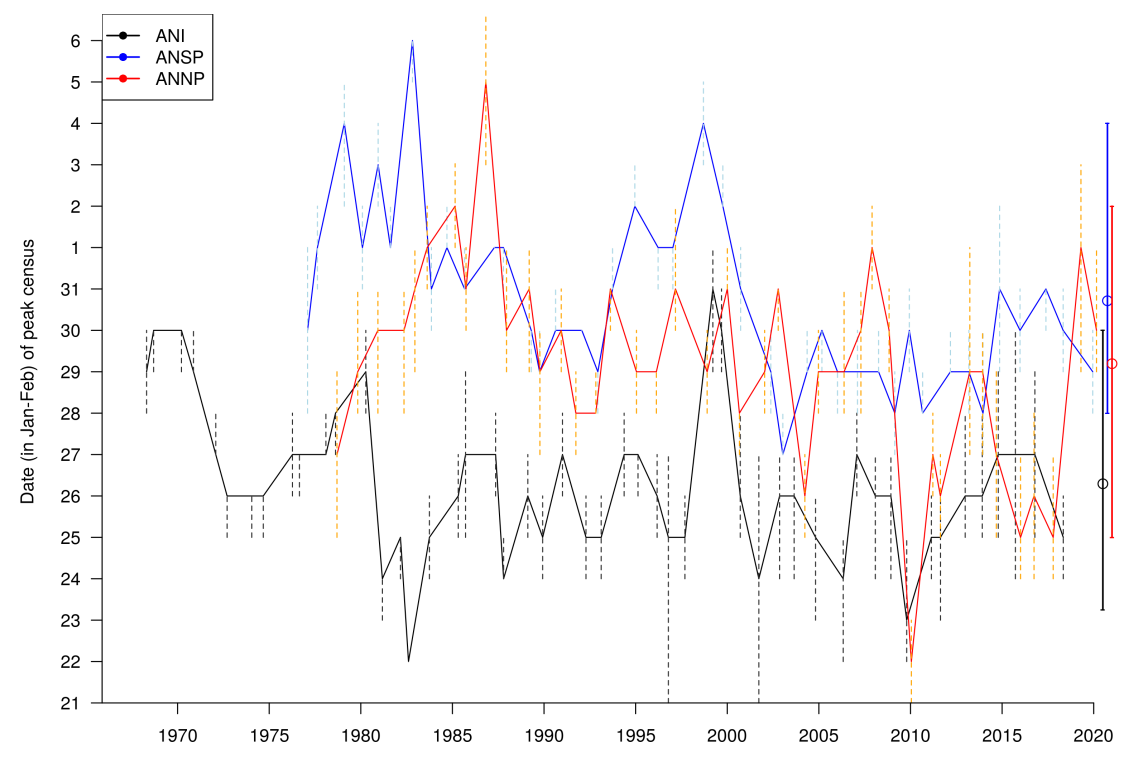

